OPEN ACCESS

Edited by:

Genku Kayo,

Tokyo City University, Japan

Reviewed by:

Mehdi Ashayeri,

Southern Illinois University

Carbondale, United States

Sujit Sikder

Leibniz Institute for Ecological Urban

and Regional Development

(IOER), Germany

*Correspondence:

Xingxing Zhang

xza@du.se

Specialty section:

This article was submitted to

Urban Energy End-Use,

a section of the journal

Frontiers in Sustainable Cities

Received: 02 February 2021

Accepted: 03 May 2021

Published: 21 June 2021

Citation:

Zhang X, Shen J, Saini PK, Lovati M, Han M, Huang $P$ and Huang Z (2021)

Digital Twin for Accelerating

Sustainability in Positive Energy

District: A Review of Simulation Tools

and Applications.

Front. Sustain. Cities 3:663269.

doi: 10.3389/frsc.2021.663269

\section{Digital Twin for Accelerating Sustainability in Positive Energy District: A Review of Simulation Tools and Applications}

\author{
Xingxing Zhang ${ }^{1 *}$, Jingchun Shen ${ }^{1}$, Puneet Kumar Saini ${ }^{1}$, Marco Lovati ${ }^{1}$, Mengjie Han ${ }^{2}$, \\ Pei Huang ${ }^{1}$ and Zhihua Huang ${ }^{3}$ \\ ${ }^{1}$ Energy and Community Building, Dalarna University, Falun, Sweden, ${ }^{2}$ Micro Data Analysis, Dalarna University, Falun, \\ Sweden, ${ }^{3}$ Telenor Connexion AB, Stockholm, Sweden
}

A digital twin is regarded as a potential solution to optimize positive energy districts (PED). This paper presents a compact review about digital twins for PED from aspects of concepts, working principles, tools/platforms, and applications, in order to address the issues of both how a digital PED twin is made and what tools can be used for a digital PED twin. Four key components of digital PED twin are identified, i.e., a virtual model, sensor network integration, data analytics, and a stakeholder layer. Very few available tools now have full functions for digital PED twin, while most tools either have a focus on industrial applications or are designed for data collection, communication and visualization based on building information models (BIM) or geographical information system (GIS). Several observations gained from successful application are that current digital PED twins can be categorized into three tiers: (1) an enhanced version of BIM model only, (2) semantic platforms for data flow, and (3) big data analysis and feedback operation. Further challenges and opportunities are found in areas of data analysis and semantic interoperability, business models, data security, and management. The outcome of the review is expected to provide useful information for further development of digital PED twins and optimizing its sustainability.

Keywords: positive energy district, digital twin, simulation tool, application, review

\section{INTRODUCTION}

Positive Energy Districts (PED) require integration of different systems and infrastructures for the optimal interactions among buildings, stakeholders, mobility, energy systems, and communication systems. According to European Strategic Energy Technology (SET) Plan Action 3.2, PEDs are the essential part of comprehensive approaches toward sustainable urbanization including technology, spatial, regulatory, financial, legal, social, and economic perspectives (Urban Europe, 2019). Urban development is moving from building solutions to PEDs in order to accelerating the clean energy transition and further achieve EU's energy and climate targets (SET-Plan action 3.2, 2018). PEDs are defined as energy-efficient and energy-flexible urban areas with surplus renewable energy production and net zero greenhouse gas emissions. 
Active information exchange and analysis will be necessary so that they would enable balancing and optimization of energy flow across the PED, integration of mobility, communication, and trading between peers, as well as engaging more stakeholders. However, these are still the main challenges to most communities and cities.

The integration of digital methods can be a solution to the challenges in PEDs. Buildings and districts can be designed to be more vibrant, efficient, and resilient if they are modeled, analyzed, and tested before they are built. A digital twin is a coupled approach for new forms of modeling and analysis based on big data and machine learning/artificial intelligence (AI). "Digital twin" refers to the creation of digital models or platforms by monitoring, modeling, and optimizing the PEDs as a complex multi-physics system based on real-time big data sets (Woods and Freas, 2019). A digital twin integrates the Internet of things (IoT), AI, machine learning, and analytics, to create living digital simulation models that update and change information as needed. A digital twin model continuously learns and updates itself from multiple sources to represent its near real-time status.

Digital twin of PEDs enables a revolutionary way to accelerate sustainability of the society, in terms of energy transition, circular economic, and climate change (Grieves and Vickers, 2016). In a digital twin platform, sensors will be set up to collect all kind of information, such as occupancy (mobility), temperature, moisture, energy consumption, renewable production, $\mathrm{CO}_{2}$ concentration, costs, waste, carbon footprint, etc., creating the "brain of PEDs." With such big data sets, digital twin model can be used to assess energy demand/supply, indoor air quality, thermal comfort, carbon emissions, expenses for operating and maintenance, building renovation and replacement needs (including recycle of waste construction materials), carbon emissions, and payback periods of energy saving measures over lifetime. This therefore optimizes PEDs' three functions in energy efficiency, energy production, and flexibility, toward energy surplus and climate neutrality.

Although there are several existing projects and reports about digital twin for PEDs, it significantly lacks a systematic review and summary about the current $\mathrm{R}$ and $\mathrm{D}$ status in this area, in order to identity current working limits and future research directions. This paper therefore presents a compact review about digital twins for PED from aspects of concepts, working principles, tools/platforms, and applications, in order to address the issues of both how digital PED twin is made and what tools can be used for digital PED twin. Further challenges and opportunities are also discussed.

\section{CONCEPT AND WORKING PRINCIPLE FOR PEDs}

A digital PED twin usually consists of four important components: (1) a virtual model of PED, (2) sensor network integration, (3) data analytics, and (4) stakeholder layer, which combines capacities of a virtual model, data management, analytics, simulation, system controls, visualization, and information sharing. Figure 1 displays a schematic of how a digital PED twin is made. The virtual model is a visualization process for a PED that can derive from 3D models extracted from building information modeling (BIM) or the custom $3 \mathrm{D}$ models of PED. The information and data within a digital PED twin can be collected and transferred by various sensor networks to create real-time monitoring, which often includes weather conditions (temperature, solar irradiation, etc.), material (new or wasted), cost, carbon emissions and footprint, facility/system status, indoor air quality (IAQ), inhabitant behavior, electric vehicle (EV) mobility, energy demand, local energy supply, and social structural information. These data will be further analyzed by and exchanged in actions/decisions with different stakeholders for operations. In this sense, the stakeholders may refer to public institutions or government, property owners or managers, inhabitants, urban planners, engineers, financial company, utilities, and service providers, etc. This dynamic interaction allows for real-time analytics, informed decision making, resource efficiency, and comfort enhancement (Khajavi et al., 2019).

Ideally, in a digital PED twin, the real-time data are collected and transferred to a data analytic center, where all kinds of data are analyzed along with their complex systems for either prediction or optimization for a number of objectives of sustainability. The majority of energy data are used in improving energy self-consumption, maximizing economic benefits, and minimizing carbon emissions, etc. The growing platform also incorporates other real-time dynamics, such as climate data, occupancy, monitored air quality data, and traffic data, as well as information about socio-demographics. For individual buildings, some of these data can be interpreted for maintaining IAQ level as a virtual model provides an extra opportunity for analytical insights for urban planners to explore the microenvironment impact of constructing new buildings. At the district level, the possibilities of generated heat and noise maps can help planners to create a more comfortable and cooler living environment for residents. In view of the features of dynamics information, it is also possible to identify enormous potential in social dimension. The representations using 3D semantic modeling are capable of improving conceptual urban design, simulating emergency, and carrying out socio-economic impact studies. The predicted or optimized information is, if necessary, sent further to stakeholders for decisions, or returned to the individual systems in reality for regular operations. Such a digital twin increases system resilience by considering interdependent systems and optimizing the decisions and operations of the future.

The considerable benefits of a digital PED twin can be anticipated. The digital twin environment will facilitate interaction and collaboration between all stakeholders involved in a PED's life cycle, by enabling integrated data, information, knowledge, and decision sharing capabilities. Such activity will further increase public and individual awareness. Since data and feedback are provided in real time, they can increase energy systems' flexibility and robustness during operation. A PED-centered digital twin can aggregate all data through the whole life cycle of a PED from design and construction (renovation), to operational and demolishment phases, hence improving the sustainability by more resourceefficient, economic and environmental decision taking (Alonso et al., 2019). 


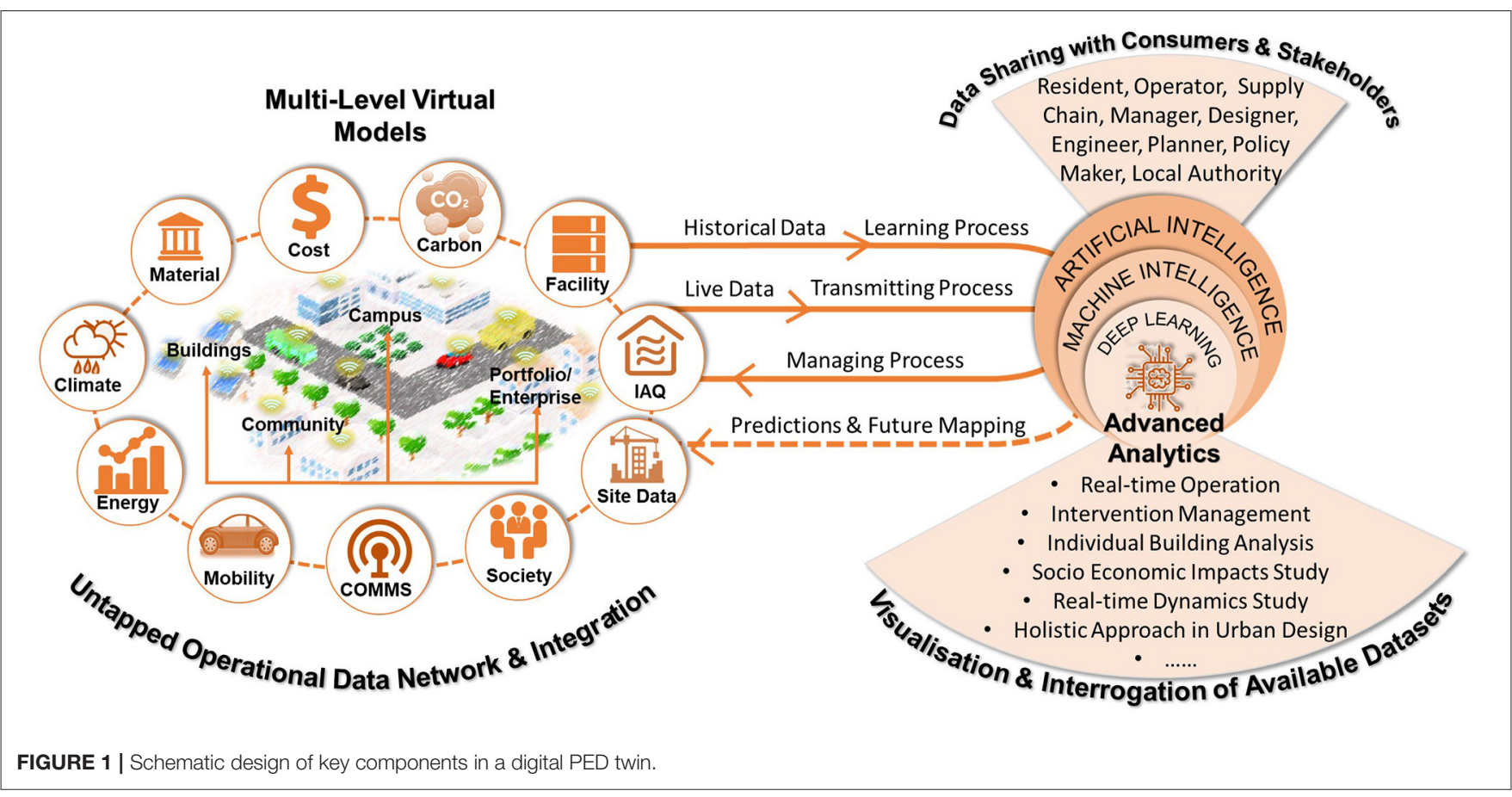

\section{DIGITAL TWIN PLATFORM AND TOOLS}

A digital twin is a combination of several modules, such as a computer model, a physical model, communication services, and data analytics. These modules work in synchronization to monitor, learn, and optimize the complete system operation. However, the implementation of the digital twin concept may require new processes, methods, and novel platforms to interact with each of these modules (Qi et al., 2019). Similar to the diversification in the 3D modeling techniques, there is no common digital twin platform. The reason is that the solution to providing a digital twin does not lie in technology but the methodology and processes used to provide these solutions (Theiet, 2020). Therefore, this section intends to provide an overview of available tools that are used for digital twin in built environment and PED context.

Intelligent communities life cycle (ICL) provides a digital platform to create, analyze, and optimize the complex energy systems. The tool can assess a broad range of configurations for building and energy systems throughout their life cycle (IESVE, 2020). The digital model is created using an intelligent community design (iCD) tool that utilizes open street maps to build a three-dimensional model and BIM interoperability of the case building. The input from $\mathrm{iCD}$ is used for dynamic simulation performance of the system across the entire building life cycle. This is enabled by the virtual environment (VE) platform to carry daylight, energy performance, and life cycle assessment of the system. Furthermore, the data from real case building are analyzed to identify operational issues, risk mitigation, and understanding system interactions using an energy management information platform.
The building minds tool provides a common platform to obtain, integrate, and analyze data from various physical systems. However, the unique features of the tool lie in the use of a common data model that makes use of AI and data democratization techniques to efficiently process the databank to provide real-time feedback to the services. Initially, the data are clustered and prioritized based on a specific process and further validated using available tools and performance indicators. The data are stored as "common data" with specific attributes and entities for further analysis. This also enables users to import and analyze data from existing digital and analogy sources to build an interoperable real-time representation of existing building entities (BuildingMinds, 2020).

Ecodomus provides a constellation of four submodules required to create a digital twin of the asset. This tool addresses the full lifetime of building from the design phase to the decommissioning phase to achieve short- and longterm efficiency gains (Ecodomus.com, 2020). The conjunction of building management software and BIM models with facility operational tools helps to understand and get critical insights on the operational systems of the building. However, the geographical information for the asset such as topography and site-wide information is obtained using Ariel equipment, such as drones to scan the field, and used as input to create a realistic digital representation of the asset.

Other platforms/tools: Most of other tools have a focus on industrial applications, such as Akselos, iTwins, and Seebo (Warner, 2018). Tools such as feature manipulation engines also provide data integration platforms with applications in multiple sectors for transportation, commercial, and utilities. Moreover, there are several existing projects looking at digital twins to address various sectors, e.g., the food, water, and energy 
nexus (CRUNCH, 2018), as well as industrial maintenance. The rest of the possible platforms or tools are mainly developed based on existing GIS models of cities or districts, BIM models, data collection networks, and communication and visualization platforms.

\section{APPLICATIONS OF DIGITAL PED TWIN}

Until 2020, there were several digital PED twin developments (Research Markets, 2020). A digital twin project in Helsinki has been developed on CityGML, which is a semantic, expandable information Open Geospatial Consortium model (Heiskanen, 2019). Rennes, France, has established a digital 3D model for various urban studies (such as for urban mediation with citizens) and for urban development purposes (such as sunshine simulation, noise modeling, and tree shadow impact on buildings) (Poppe, 2016). Rotterdam, Holland, applies a digital twin for managing the city's infrastructure assets (Research Markets, 2020). Pasadena, California, in the USA, has developed a useful supervisory tool for the city's public sector players. Meanwhile, Portland, Oregon, in the USA, plans to construct a digital transportation activated by residents' cellular data (Fischer, 2019). The waterfront in Toronto, Canada, is using digital twin technology to launch a public advocate of waterfront revitalization, along with the urban innovation organization Sidewalk Labs (Doyle, 2019). A project in Dubai focuses on users' experience by using a digital twin. Jaipur, India, is using a digital twin project for urban planning and supervision (Research Markets, 2020). In Shanghai, China, immersive digital twins in railway engineering have established new practices to deliver a sewage treatment plant (Parrott and Warshaw, 2017). A detailed description of specific digital twin projects can be found in Table 1.

From the pilot projects demonstrated, it can be concluded that the digital twin concept usually consists of three distinct parts: (1) the physical asset, from community to city; (2) the logical constructed digital/virtual product, or the associated virtual three-dimensional digital replica; and (3) communications in between contained by specific applications. The communications usually take place on certain types of platform. The most popular digital twin city solution suppliers are Alphabet, Autodesk and Esri, Bentley, Cityzenith, Dassault systems, Engie Ineo/Siradel, Microsoft, NTT Data Corporation, Siemens, and IESVE (Research Markets, 2020; University of Cambridge, 2020).

The first-tier generation works almost like an enhanced version of BIM on construction sites for data. The limitations lie in information requirements for subsequent life cycle stages and extensibility in associated complex computations. Typically, the evolved maturity elements at this stage are (Savian, 2020):

- reality as-built data set capture (e.g., point cloud, drones, photogrammetry, or drawings/sketches);

- spatial information connected to 3D model;

- connect model to more static data (e.g. documents, drawings, asset management systems);
The second-tier generation moves a major progress forward with intelligent semantic platforms, providing a primary knowledge base development. But there are inadequate actuation capabilities in dealing with complex information interactions. Typically, the evolved maturity elements at this stage are added to Savian (2020):

- enrich with dynamic one-directional data flow (e.g., from the Internet of things, embedded sensors);

- establish two-way data integration and interaction (human-tomachine and machine-to-machine).

The third-tier generation has advanced knowledge leverages with the use of AI-enabled agents. Relying on the previous intelligent semantic platform, it elaborates AI technologies, such as machine learning, deep learning, data mining, and analysis capabilities to construct a self-reliant, self-updatable, and self-learning digital twin projects. Typically, the evolved maturity elements at this stage can be finalized with aspirational autonomous operations and maintenance (Savian, 2020).

Meanwhile, the connections between the physical items and the digital or virtual replica are continued data flows that stream from the physical product to the digital or virtual product, as well as information generated from the digital or virtual platform to the physical environment. In summary, the primary functions collected from the projects mentioned are prediction, simulation, monitoring, lifecycle, sensing, optimization, the Internet of things, $\mathrm{AI}, \mathrm{BIM}$, knowledge processing with data sets, and web-based data integration (Boje et al., 2020). Digital twins have evolved from monitoring platforms, intelligent semantic platforms, and agent-driven socio-technical platforms. The evolution represents a continuous growth in terms of both lifecycle and supply chain integration (Boje et al., 2020).

\section{CHALLENGE AND OPPORTUNITY}

\section{Data Analysis and Semantic Interoperability}

It is observed that most of the existing studies and applications emphasize the creation of a digital PED twin, rather than how to optimize it for operation and maintenance. Most studies have completed excellent virtual models of PED and integrated largescale sensor network, but knowledge and skill in data analysis and interoperable interaction with different stakeholders are still lacking.

The ability of a digital PED twin is to capture the complexand-dynamic relationships of different components in PEDs, which allows new levels of analysis of complex environments. However, now, also lacking are the studies to run analysis of real-time operations and different future scenarios, which aim to explore their impacts across the PED systems for new insights that enhance our ability to take more holistic approaches to building PED design, energy strategies, and transportation planning, etc. For instance, how inhabitants change their mobility behavior in response to the increase of EV numbers; the impact of distributed PV installation on local network and storage systems, as well as local electricity market via different business models; 


\begin{tabular}{|c|c|c|c|c|c|}
\hline References & $\begin{array}{l}\text { Dundalk Institute of } \\
\text { Technology, Ireland (IESVE, } \\
\text { 2017) }\end{array}$ & $\begin{array}{l}\text { West Campus of University of } \\
\text { Cambridge in UK (Nochta et al., 2019; } \\
\text { Institute for Manufacturing, University } \\
\text { of Cambridge, 2020) }\end{array}$ & $\begin{array}{l}\text { Boston 3D Model, USA } \\
\text { (Patrick, 2018) }\end{array}$ & $\begin{array}{l}\text { New South Wales state, } \\
\text { Australia (New South Wales } \\
\text { Government (NSWG), 2019; } \\
\text { Policy Lab Spatial Services, } \\
\text { 2019) }\end{array}$ & $\begin{array}{l}\text { Virtual Singapore (Qi et al., 2019; } \\
\text { Systèmes, 2019; National } \\
\text { Research Foundation (NRF) and } \\
\text { Prime Minister's Office Singapore, } \\
\text { 2021) }\end{array}$ \\
\hline Project description & $\begin{array}{l}\text { - Virtual campus energy model } \\
\text { for yearly energy supply and } \\
\text { demand. } \\
\text { - Scenarios studies include } \\
\text { lifecycle Cost, Net Present } \\
\text { Value, projected savings and } \\
\text { return of investment (ROI) over } \\
\text { a } 20 \text {-year period. }\end{array}$ & $\begin{array}{l}\text { - City level digital twins use west campus } \\
\text { of University of Cambridge in UK a case } \\
\text { study to investigate how existing } \\
\text { systems are influenced by digital } \\
\text { solutions. } \\
\text { - Focus on social, economic and } \\
\text { environmental outcomes that meet } \\
\text { citizens' needs and respond to } \\
\text { contemporary urban challenges. }\end{array}$ & $\begin{array}{l}\text { - City-level digital twins focus on } \\
\text { environmental impacts. } \\
\text { - GIS for public consumption. } \\
\text { - Open data includes parcel } \\
\text { ownership, districts, historic } \\
\text { landmarks, and open space. } \\
\text { - Analytical data includes } \\
\text { sea-level rise projection. }\end{array}$ & $\begin{array}{l}\text { - City-level digital twins to } \\
\text { facilitate better planning, } \\
\text { design and modeling for future } \\
\text { needs. } \\
\text { - Include digital visualizations of } \\
\text { the local government areas. } \\
\text { - Integration of live transport } \\
\text { feeds as well as infrastructure } \\
\text { building models. }\end{array}$ & $\begin{array}{l}\text { - Country/City-level digital twins } \\
\text { Include typical map and land data, } \\
\text { real-time dynamics, as well as } \\
\text { information about demographics, } \\
\text { climate or traffic. }\end{array}$ \\
\hline Platform & $\begin{array}{l}\text { Intelligent Communities } \\
\text { Lifecycle (ICL) }\end{array}$ & $\begin{array}{l}\text { (1) Bentley for 3D BIM modeling; (2) } \\
\text { GeoSLAM for detailed context capture } \\
\text { scan; (3) Topcon for a low-level-detailed } \\
\text { 3D geometry and photogrammetry using } \\
\text { drone and vehicle-based scanning and } \\
\text { camera devices; and (4) Redbite for asset } \\
\text { management solution }\end{array}$ & GIS-based 3D city model & Open sourced TerriaJS & 3D EXPERIENCity platform \\
\hline Objectives & $\begin{array}{l}\text { - Energy supply and demand; } \\
\text { - Transformer performance; } \\
\text { - Energy storage performance; } \\
\text { - Simulate energy demand data } \\
\text { where it was missing or } \\
\text { incomplete; } \\
\text { - Validate pre-existing } \\
\text { renewable investments and } \\
\text { calculate ROI on } \\
\text { improvement options. }\end{array}$ & $\begin{array}{l}\text { - Analysis of infrastructure performance } \\
\text { and use on organizational productivity; } \\
\text { - Provide the foundation for integrating } \\
\text { city-scale data to optimize city services } \\
\text { such as power, waste, transport and } \\
\text { understand the impact on wider social } \\
\text { and economic outcomes; } \\
\text { - Establish a "research capability } \\
\text { platform" for researchers to understand } \\
\text { and address the major challenges in } \\
\text { implementing digital technologies at } \\
\text { scale; } \\
\text { - Improve the management and use of } \\
\text { infrastructure systems. }\end{array}$ & $\begin{array}{l}\text { - Capture the entire city and } \\
\text { determine real-world impacts } \\
\text { to make timely decisions. } \\
\text { - Both quantitative and } \\
\text { qualitative analysis workflows. } \\
\text { - Designers are expected to use } \\
\text { metrics and a standardized } \\
\text { process and procedure to } \\
\text { evaluate projects, including } \\
\text { planning and development, } \\
\text { flood modeling, shadow } \\
\text { studies, and } \\
\text { line-of-sight evaluation. }\end{array}$ & $\begin{array}{l}\text { - Upgrade the existing state's } \\
\text { spatial data from 2D to } \\
\text { real-time 3D and 4D. } \\
\text { - Engage with government } \\
\text { agencies and industry bodies } \\
\text { offering benefits at national, } \\
\text { state and local government } \\
\text { levels; } \\
\text { - Disaster management through } \\
\text { to bus schedules for city's } \\
\text { future needs. }\end{array}$ & $\begin{array}{l}\text { - Design better urban centers. } \\
\text { - Optimizing a better accessibility } \\
\text { solution in a specific area without } \\
\text { any construction work; } \\
\text { - Estimating emergency situations } \\
\text { and establishing the most suitable } \\
\text { evacuation protocols; } \\
\text { - Providing real-time monitoring. }\end{array}$ \\
\hline Limitations & $\begin{array}{l}\text { Only limited untapped } \\
\text { operational data can be } \\
\text { homogenized from any source } \\
\text { in any format into virtual } \\
\text { campus model. }\end{array}$ & $\begin{array}{l}\text { - The pluralized private sector data } \\
\text { owners } \\
\text { - The lack of data sharing frameworks } \\
\text { in place. }\end{array}$ & $\begin{array}{l}\text { The applications are limited } \\
\text { only for tailored shadow } \\
\text { impact analysis and planning } \\
\text { review solutions. }\end{array}$ & $\begin{array}{l}\text { - The limited accuracy } \\
\text { - Challenges in interoperability } \\
\text { with existing assets, products, } \\
\text { systems and processes; } \\
\text { - Data formats have short } \\
\text { lifecycles. } \\
\text { - Ownership and data sharing } \\
\text { arrangements are challenging. } \\
\text { - The affordability is an issue } \\
\text { during design and } \\
\text { build process. }\end{array}$ & $\begin{array}{l}\text { - Requires a substantial resources for } \\
\text { its development. } \\
\text { - Complex modeling. }\end{array}$ \\
\hline
\end{tabular}

- Simulate energy demand data

-

calculate $\mathrm{ROI}$ on

improvement options. 


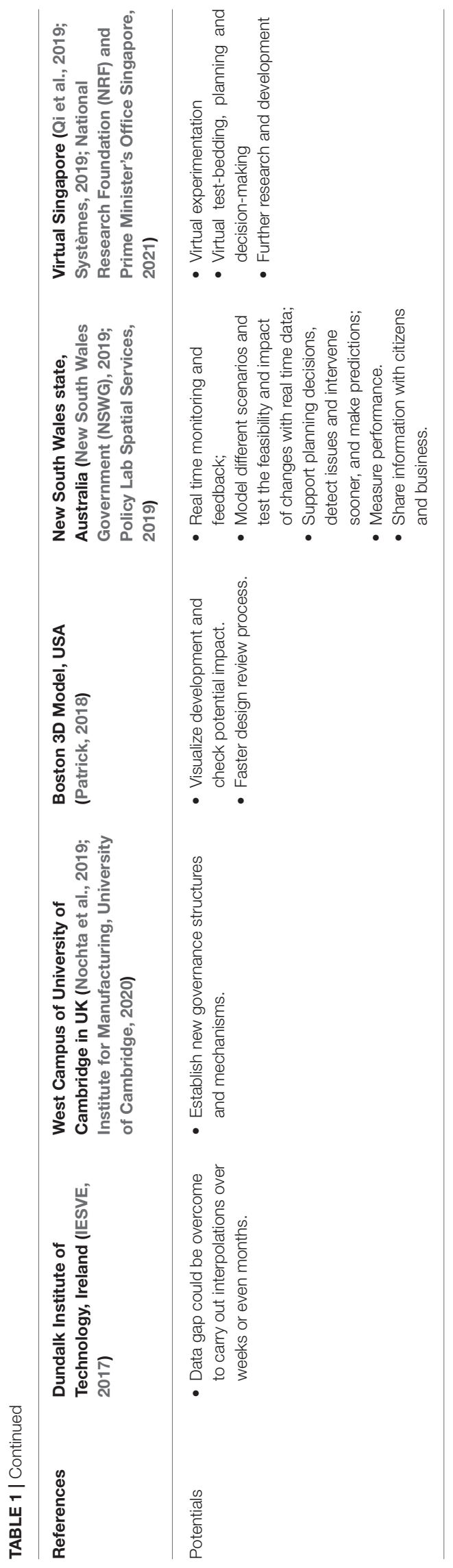

the impact of future climate, and the way to adapt PED to the future scenario. This will need more and more advanced machine learning and AI approaches to provide another level of analysis of the complex systems and component relationships that would be nearly impossible to realize in a real-world environment (Woods and Freas, 2019).

Current digital PED twins lack a semantic model to standardize concept descriptions and data representations for interoperable interactions with different stakeholders and energy information communication or management. Semantic models and their applications are now mostly designed to facilitate planning or analysis of urban energy systems through simulation or information representation and exchange, rather than facilitating energy-related operation and management or as part of a complex event processing system (Howell et al., 2017). Semantic heterogeneity between vocabularies and data representations is a common issue in existing digital twin models.

\section{Business Models and Economic Analysis}

Economic feasibility studies and business models of digital PED twins are also lacking. The concept of a digital twin will transform the business of energy production and supply from a centralized level to a decentralized one (Richter, 2013). Renewable energy systems and the energy saving technologies in a PED have an initial cost and also a savings potential during their lifetime. The business model of these technologies should consider the investment and maintenance costs with the savings (Qin et al., 2017) and revenues (IRENA, 2019). The costs associated with the creation of a digital twin are already considered when designing a PED energy system as most of the infrastructure needed for the operation is necessary in a decentralized energy market, regardless of the ownership structure of the infrastructure. In view of the profound interdependence of energy and monetary fluxes, it is paramount to have a detailed knowledge, hence a model, of the energy flows in a local grid (Roberts et al., 2019). In recent years researchers have started to study the interactions among prosumers within an energy producing district (Zhang et al., 2018; Jing et al., 2020), by proposing different business models, such as power purchase agreements (PPA), net-metering mechanisms, and peer-to-peer (P2P) trading mechanisms. Once the sensors and models of the local energy system are put in place, the use of a digital twin can provide a series of benefits from the design to the operation phase, which will facilitate energy sharing and trading based on different business models. Using a digital twin during the design phase helps to predict performance during the operation phase. Continuous learning can improve the profitability of energy investments and reduce investment risk.

\section{Data Security and Management}

PEDs gather dynamic energy and other information at a district level and generate a great amount of data when they are digitalized, which requires cloud storage and computing. Potential issues, such as insufficiency of data, accessibility, and governance aspects are challenging to data security and management. 
Despite its potential in the collection of big data sets, there is a fundamental gap regarding data acquisition in PED regarding different dimensions, such as technical, economic, environmental, and social aspects. Under data protection regulations, it is not possible to collect all the parameters that are necessary for modeling and feedback operations (Lock et al., 2019). The concept of PED is still in its early stages, and the acquisition of high-quality data is usually difficult since data collection is costly and data management is time consuming. Without sufficient data at a micro-level, the optimization methods and decision making will be biased. However, advanced data generation mechanisms can be used to mitigate the situation (Han et al., 2021).

Providing authentication, authorization, and access control for data stored in the cloud may increase data security in terms of confidentiality, integrity, and availability. However, when multiple organizations share the data, there is a risk of misusing the data (Rao and Selvamani, 2015). First. confidentiality protects information from being accessed by unauthorized parties. It is an essential requirement to ensure the security of data in cloud storage and computing (Aloraini and Hammoudeh, 2017). Applying data encryption can limit the access to stored data for PEDs. In order to ensure the effective use of encryption, much consideration should be put into the encryption algorithms and key strength. As cloud computing involves large amounts of data transmission, storage, and handling, it also needs to consider processing speed and computational efficiency of encrypting large amounts of data (Chen and Zhao, 2012). Second, data integrity refers to the data and information storage in the cloud being valid and protected from modification or changes (Balogh and Turcani, 2016). A digital PED twin is an integrated system where digital information for each subsystem is highly correlated. Any alteration of data may jeopardize the connections between systems. Thus, cloud service providers should check and maintain the data and computation regularly. However, it is still a challenge to predict any future modification to the data based on historical performance. Last, availability ensures that authorized users have access to the information. PEDs comprise multiple agents, and cloud computing is also moving to multicloud computing (Aldossary and Allen, 2016). The subsystems

\section{REFERENCES}

Aldossary, S., and Allen, W. (2016). Data security, privacy, availability and integrity in cloud computing: issues and current solutions. Int. J. Adv. Comput. Sci. Appl. 7, 485-498. doi: 10.14569/IJACSA.2016. 070464

Alonso, R., Borras, M., Koppelaar, R., Lodigiani, A., Loscos, E., and Yöntem, E. (2019). SPHERE: BIM digital twin platform. Proceedings 20:9. doi: 10.3390/proceedings2019020009

Aloraini, F., and Hammoudeh, M. (2017). "A survey on data confidentiality and privacy in cloud computing," in ICFNDS '17 (Cambridge), 1-7. doi: 10.1145/3102304. 3102314

Balogh, Z., and Turcani, M. (2016). Modeling of data security in cloud computing. Proc. Annu. IEEE Syst. Confer. 2016, 1-6. doi: 10.1109/SYSCON.2016.74 90658 may work independently, and they need a system that is always available. Substantial efforts are still needed for making the transition from single-cloud to multi-cloud computing.

\section{CONCLUSION}

This paper presents a compact review about digital twins for PEDs from aspects of concepts, working principles, tools or platforms, and applications, in order to address the issues of both how a digital PED twin is made and what tools can be used for a digital PED twin. A few available tools and platforms are reviewed for digital twins in built environments and PEDs, such as ICL, Building minds, and Ecodomus. Other platforms and tools either have a focus on industrial applications or are mainly developed based on existing GIS models of cities or districts, BIM models, data collection networks, and data communication and visualization platforms. Several successful applications of digital PED twins are summarized, where lessons and observations are gained so that digital PED twins can be categorized in three tiers: (1) an enhanced version of BIM model only, (2) semantic platforms for data flow, and (3) AI-enabled agents for data analysis and feedback operation. Further challenges and opportunities lie in data analysis and semantic interoperability, business models, data security, and management.

\section{AUTHOR CONTRIBUTIONS}

$\mathrm{XZ}$ contributed to supervision, concept development, structuring, and writing. JS and PS contributed to the review of simulation tools and applications. $\mathrm{ML}, \mathrm{MH}, \mathrm{PH}$, and $\mathrm{ZH}$ are dedicated to future research directions. All authors contributed to the article and approved the submitted version.

\section{FUNDING}

This research has received funding from Swedish Energy Agency (Grant Number 8569501), J. Gust. Richert foundation in Sweden (Grant Number 2020-00586), and IMMA project of research network, Dalarna University, Sweden.
Boje, C., Guerriero, A., Kubicki, S., and Rezgui, Y. (2020). Towards a semantic construction digital twin: directions for future research. Automation Construct. 114:103179. doi: 10.1016/j.autcon.2020.103179

BuildingMinds (2020). How Digital Building Twins Accelerate Your Sustainability. Buildingminds. Available online at: https://buildingminds.com/article/howdigital-building-twins-accelerate-building-performance (accessed May 4, 2020).

Chen, D., and Zhao, H. (2012). "Data security and privacy protection issues in cloud computing," in 2012 International Conference on Computer Science and Electronics Engineering (Hangzhou). 647-651. doi: 10.1109/ICCSEE.2012.193

CRUNCH (2018). CRUNCH. Available online at: http://www.fwe-nexus.eu/ workshops.php (accessed May 4, 2020).

Doyle, S. (2019). Digital Urban Planning: Twins Help Make Sense of Smart Cities. Available online at: https://eandt.theiet.org/content/articles/2019/01/digitalurban-planning-twins-help-make-sense-of-smart-cities/ (Accessed on March 31, 2020). 
Ecodomus.com (2020). Ecodomus FM - Ecodomus. Available online at: https:// www.ecodomus.com/portal (accessed May 4, 2020).

Fischer, R. (2019). Digital Transportation: The Future of Urban Mobility. Available online at: https://usgtima.org/perspectives/digital-transportation-the-futureof-urban-mobility/ (accessed March 31, 2020).

Grieves, M., and Vickers, J. (2016). "Digital twin: mitigating unpredictable, undesirable emergent behavior in complex systems," in Trans-Disciplinary Perspectives on System Complexity (Springer).

Han, M., Wang, Z., and Zhang, X. (2021). An approach to data acquisition for urban building energy modeling using a gaussian mixture model and expectation-maximization algorithm. Buildings 11:30. doi: 10.3390/buildings11010030

Heiskanen, A. (2019). Helsinki is Building a Digital Twin of the City. Available online at: https://aec-business.com/helsinki-is-building-a-digitaltwin-of-the-city/ (accessed March 31, 2020).

Howell, S., Rezgui, Y., Hippolyte, J. L., Jayan, B., and Li, H. (2017). Towards the next generation of smart grids: semantic and holonic multiagent management of distributed energy resources. Renew. Sustain. Energy Rev. 77, 193-214. doi: 10.1016/j.rser.2017.03.107

IESVE (2017). Dundalk Institute of Technology. Available online at: https://www. iesve.com/icl/case-studies/2886/dundalk-institute-of-tecnhnology (accessed March 30, 2020).

IESVE (2020). The ICL Is Here! The New Environmental Digital Twin For Healthy Sustainable Communities | Discoveries | IES. Available online at: https://www.iesve.com/discoveries/article/7734/the-icl-is-here (accessed May 4, 2020).

Institute for Manufacturing, University of Cambridge (2020). Infrastructure Digital Twins. Available online at: https://www.ifm.eng.cam.ac.uk/research/ asset-management/research-projects/infrastructure-digital-twins/ (Accessed on March 31, 2020).

IRENA (2019). Renewable Power Generation Costs in 2018. Abu Dhabi: International Renewable Energy Agency.

Jing, R., Xie, M. N., Wang, F. X., and Chen, L. X. (2020). Fair P2P energy trading between residential and commercial multi-energy systems enabling integrated demand-side management. Appl. Energy 262:114551. doi: 10.1016/j.apenergy.2020.114551

Khajavi, S. H., Motlagh, N. H., Jaribion, A., Werner, L. C., and Holmström, J. (2019). Digital twin: vision, benefits, boundaries, and creation for buildings. IEEE Access. 7, 147406-147419. doi: 10.1109/ACCESS.2019.2946515

Lock, O., Bednarz, T., and Pettit, C. (2019). HoloCity - Exploring the Use of Augmented Reality Cityscapes for Collaborative Understanding of High-Volume Urban Sensor Data. doi: 10.1145/3359997.3365734

National Research Foundation (NRF) and Prime Minister's Office Singapore (2021). Virtual Singapore. Available online at: https://www.nrf.gov.sg/ programmes/virtual-singapore\#: :text=Virtual\%20Singapore\%20is\%20a \%20dynamic, private\%2C\%20people\%20and\%20research\%20sectors (accessed March 15, 2021).

New South Wales Government (NSWG) (2019). Emerging Technology Guide: Digital Twin. Available online at: https://www.digital.nsw.gov.au/ transformation/policy-lab/emerging-technology-guide-digital-twin (accessed March 15, 2021).

Nochta, T., Badstuber, N., and Wahby, N. (2019). On the Governance of City Digital Twins Insights From the Cambridge Case Study, CDBB (Centre for Digital Built Britain), July 2019. Cambridge: University of Cambridge, Series No: CDBB_WP_012.

Parrott, A., and Warshaw, L. (2017). Industry 4.0 and the Digital TwinManufacturing Meets Its Match, s.l. New York, NY: Deloitte University Press.

Patrick, B. (2018). Meet Boston's Digital Twin. Available online at: https://www. esri.com/about/newsroom/blog/3d-gis-boston-digital-twin/ (accessed March 30, 2020).

Policy Lab and Spatial Services (2019). Twinning! Spatial Services Has Created a Digital Twin of NSW. Available online at: https://www.digital.nsw.gov. au/article/twinning-spatial-services-has-created-digital-twin-nsw (accessed March 30, 2020).

Poppe, S. (2016). Digital 3D Modelling of Rennes Metropole. Available online at: https://sharingcities.eu/eurocities/allcontent/Digital-3Dmodelling-of-Rennes-Metropole-WSPO-A8JDUM (accessed March 31, 2020).
Qi, Q., Tao, F., Hu, T., Anwer, N., Liu, A., Wei, Y., et al. (2019). Enabling technologies and tools for digital twin. J. Manufac. Syst. 58, 3-21. doi: 10.1016/j.jmsy.2019.10.001

Qin, Q., Liang, F., Li, L., and Wei, Y. M. (2017). Selection of energy performance contracting business models: a behavioral decision-making approach. Renew. Sustain. Energy Rev. 72, 422-433. doi: 10.1016/j.rser.2017. 01.058

Rao, R. V., and Selvamani, K. (2015). "Data security challenges and its solutions in cloud computing," in International Conference on Intelligent Computing, Communication \& Convergence, 204-209. doi: 10.1016/j.procs.2015.04.171

Research and Markets (2020). Digital Twin Cities. 2020: The Global Ecosystem, City-backed Projects, Main Application Sectors, and Solution Suppliers, s.l. Dublin: Research and Markets.

Richter, M. (2013). Business model innovation for sustainable energy: German utilities and renewable energy. Energy Policy 62, 1226-1237. doi: 10.1016/j.enpol.2013.05.038

Roberts, M. B., Bruce, A., and MacGill, I. (2019). A comparison of arrangements for increasing self-consumption and maximising the value of distributed photovoltaics on apartment buildings. Solar Energy 193, 372-386. doi: 10.1016/j.solener.2019.09.067

Savian, C. (2020). Digital Twins for the Built Environment: An Introduction to the Opportunities, Benefits, Challenges and Risks. Hertfordshire: The Institution of Engineering and Technology.

SET-Plan action 3.2 (2018). Implementation Plan: Europe to Become a Global Role Model in Integrated, Innovative Solution for the Planning, Deployment, and Replication of Positive Energy Districts. Available online at: https://setis.ec. europa.eu/system/files/2021-04/setplan_smartcities_implementationplan.pdf (accessed March 11, 2020).

Systèmes, D. (2019). Meet Virtual Singapore, the City's 3D Digital Twin. Available online at: https://www.smartcitylab.com/blog/digital-transformation/ singapore-experiments-with-its-digital-twin-to-improve-city-life/ (accessed March 30, 2020).

Theiet (2020). Built Environment. Available online at: https://www.theiet.org/ impact-society/sectors/built-environment/?utm_source=redirect\&utm_ medium=legacyredirects\&utm_campaign=2019relaunch (accessed May 4, 2020).

University of Cambridge (2020). Infrastructure Digital Twins. Available online at: https://www.ifm.eng.cam.ac.uk/research/asset-management/researchprojects/infrastructure-digital-twins/ (accessed March 31, 2020).

Urban Europe (2019). Framework Definition for Positive Energy Districts and Neighbourhoods. Available online at: https://jpi-urbaneurope.eu/news/ consultation-on-the-framework-definition-for-positive-energy-districtsand-neighbourhoods/ (accessed February18, 2020).

Warner, T. (2018). Innovating the Future With Canada'S Digital Technology Supercluster | Safe Software. Available online at: https://www.safe.com/ blog/2018/10/innovating-future-canadas-digital-technology-supercluster/ (accessed May 4, 2020).

Woods, E., and Freas, B. (2019). White Paper of Creating Zero Carbon Communities: The Role of Digital Twins, Commissioned by Integrated Environmental Solutions Limited. Available online at: https://learn.iesve.com/ digital-twin-white-paper/ (accessed September 2020).

Zhang, C., Wu, J., Zhou, Y., Cheng, M., and Long, C. (2018). Peerto-peer energy trading in a microgrid. Appl. Energy 220, 1-12. doi: 10.1016/j.apenergy.2018.03.010

Conflict of Interest: $\mathrm{ZH}$ is employed by the company Telenor Connexion AB.

The remaining authors declare that the research was conducted in the absence of any commercial or financial relationships that could be construed as a potential conflict of interest.

Copyright (c) 2021 Zhang, Shen, Saini, Lovati, Han, Huang and Huang. This is an open-access article distributed under the terms of the Creative Commons Attribution License (CC BY). The use, distribution or reproduction in other forums is permitted, provided the original author(s) and the copyright owner(s) are credited and that the original publication in this journal is cited, in accordance with accepted academic practice. No use, distribution or reproduction is permitted which does not comply with these terms. 